\title{
pH-Controllable Bioelectrocatalysis Based on Surface Charge and Conformation Switching of Nonelectroactive Protein
}

\author{
Hai $\mathrm{Wu}^{1,2^{*}}$, Xiang $\mathrm{Li}^{1}$, Miaomiao Chen ${ }^{1}$, Chang Wang, ${ }^{1}$ Hong Zhang ${ }^{1}$, Suhua Fan ${ }^{1}$, Yongwen $\mathrm{Li}^{3}$ \\ ${ }^{1}$ School of Chemistry and Materials Engineering, Fuyang Normal University, Fuyang, Anhui 236037 , \\ PR China \\ ${ }^{2}$ State Key Laboratory of Chemo/Biosensing and Chemometrics, Hunan University, Changsha \\ 410082, PR China \\ ${ }^{3}$ Key Laboratory of Embryo Development and Reproductive Regulation of Anhui Province, Fuyang \\ Normal University, Fuyang, Anhui 236037, PR China \\ *E-mail: wuhai317@126.com
}

Received: 10 November 2017 / Accepted: 10 January 2018 / Published: 5 February 2018

\begin{abstract}
Lysozyme (Lys), a nonelectroactive protein, was covalently bonded with L-cysteine (L-Cys) selfassembled monolayers (SAMs) on Au electrode to obtain the $\mathrm{pH}$-switchable interface (Lys/L-Cys). Based on the surface charge and conformational switching of Lys at $\mathrm{pH} 6.19$ and 12.13, the Lys/L$\mathrm{Cys} / \mathrm{Au}$ electrode exhibited a $\mathrm{pH}$-sensitive on-off behavior toward the electroactive probe of $\mathrm{Fe}(\mathrm{CN})_{6}{ }^{3-}$. As $\mathrm{pH}$ was lower or higher than the isoelectronic point (pI 11.0) of Lys, Lys on electrode was positively or negatively charged by the protonation or deprotonation of amino acid residues. Furthermore, protein conformation was reversibly folded or unfolded to the native state and unfolded intermediate accordingly. Consequently, the electrostatic force between Lys and probe of $\mathrm{Fe}(\mathrm{CN})_{6}{ }^{3-}$ and reversible conformational change of Lys are responsible for the $\mathrm{pH}$-sensitive on-off behavior of Lys/L-Cys/Au interface. Moreover, the switchable properties of Lys/L-Cys/Au electrode were used to realize $\mathrm{pH}$-controlled electrochemical reduction of $\mathrm{H}_{2} \mathrm{O}_{2}$ and exhibited high sensitivity for the bioelectrocatalytic reduction of $\mathrm{H}_{2} \mathrm{O}_{2}$. In the linear range of $0.2-11.2 \mathrm{mM}$, the response sensitivity was calculated to be $379 \mu \mathrm{A} \mathrm{mM} \mathrm{cm}^{-2}$. The investigations in the mechanism for $\mathrm{pH}$-sensitive behavior and electrocatalysis of the interface suggest that the nonelectroactive Lys/L-Cys film provides potential for fabricating novel switchable electrochemical biosensors and bioelectronic devices.
\end{abstract}

Keywords: Bioelectrocatalysis, Electrochemical sensor, pH-switchable behavior, Protein, Lysozyme

\section{INTRODUCTION}

Reversibly switchable biocatalysis has been applied into electroanalytical chemistry for developing controllable biosensors and amplifing signal [1]. For this researching objective, one of the major challenges is to realize the controllable or stimuli-responsive bioelectrocatalysis [2]. Among 
various external stimuli such as $\mathrm{pH}$ [1], ionic strength [3], temperature [4], and electric field [5], $\mathrm{pH}$ has been frequently used due to the simplicity and accuracy [1,6]. At the same time, a lot of functional materials, electron-transfer mediators, redox enzymes, and proteins have been used to modify electrodes and amplify the electrical signal [7-10]. For example, Song's group used chitosan-reduced graphene oxide/concanavalin A to construct $\mathrm{pH}$-switchable sensor for the detections of glucose and urea in the same sample [1]. Katz's groups used the poly(4-vinyl pyridine) (P4VP)-brush-modified indium tin oxide (ITO) electrode to reversibly switch the interfacial activity, which was based on the $\mathrm{pH}$-sensitive change in the structure of P4VP polymer brush [11]. Hu's groups reported a series of researches on $\mathrm{pH}$-controlled bioelectrocatalysis by assembling layer-by-layer films of proteins, enzymes, and polyelectrolyte on electrodes, which relied on the electrostatic interactions or structural change of polyelectrolyte with external stimuli [12-14]. These intelligent surfaces were constructed by self-assembly, electrostatic interaction, and adsorption of functional molecules. Therefore, the effective immobilization of the functional molecules on the surface of electrode and the stability of modified interface are highly desired for development of the electrochemical biosensors.

According to the mechanism, the strategies for constructing these systems include the reversible changes in conformation, volume, electric charge, solubility, and other properties induced by external stimuli [14]. Proteins, which are inherently biocompatible in a biological body, have been used for fabricating various electrochemical biosensors $[15,16]$. Especially, redox proteins including hemoglobin, cytochrome c, and myoglobin have been extensively applied in the construction of electrochemical biosensors, which is ascribed to the electroactivity of redox proteins $[10,16]$. But it is difficult for the nonelectroactive proteins to construct the switchable electrochemical devices, causing a few previous reports. Moreover, the conformational alteration of protein with external stimuli does not receive enough attention. We have reported that the redox proteins on electrodes showed conformational changes with external stimuli such as $\mathrm{pH}$, urea, guanidine hydrochloride, and other unfolded reagents, which caused obvious change in electrochemical catalysis $[15,17,18]$.

As an important nonelectroactive protein, chicken egg-white lysozyme (Lys) contains a single polypeptide chain with 129 amino acid residues, which folds into a globular conformation by secondary bond in the native state [19]. The unfolding mechanism of Lys has been investigated and it was most stable in weakly acidic conditions [20-22]. In this work, Lys was used as a model protein and immobilized onto a gold electrode by incorporation of covalent bond and self assembly, which are easy, stable, effective, and frequently-used methods to fabricate electrochemical sensors. The resulted interface exhibited good $\mathrm{pH}$-sensitive on-off behavior towards the electroactive $\mathrm{Fe}(\mathrm{CN})_{6}{ }^{3-}$ probe and showed high sensitivity for the bioelectrocatalytic reduction of $\mathrm{H}_{2} \mathrm{O}_{2}$. Furthermore, for better understanding the mechanism of the $\mathrm{pH}$-dependent properties, the conformation of Lys was explored and evaluated by changing the surrounding $\mathrm{pH}$.

\section{EXPERIMENTAL}

\subsection{Materials}

Chicken egg-white lysozyme (Lys), L-Cysteine hydrochloride (L-Cys) was purchased from

J\&K Chemical Ltd. (Shanghai). N-hydroxysuccinimidyl sodium salt (NHS) and 1-(3- 
dimethylaminopropyl)-3-ethylcarbodiimide hydrochloride (EDC) were obtained from Aldrich. Potassium ferricyanide $\left(\mathrm{K}_{3} \mathrm{Fe}(\mathrm{CN})_{6}\right)$ and $\mathrm{H}_{2} \mathrm{O}_{2}$ (30\%) were purchased from Sinopharm Chemical Reagent Co. Ltd (Shanghai). $\mathrm{K}_{3} \mathrm{Fe}(\mathrm{CN})_{6}$ solution $(1.0 \mathrm{mM})$ containing $0.1 \mathrm{M} \mathrm{KCl}$ was used as an electrolyte and its $\mathrm{pH}$ was adjused by $\mathrm{HCl}$ and $\mathrm{NaOH}$. Aqueous solutions were prepared by high purity water.

\subsection{Fabrication of the prepared electrodes}

The gold electrode (Au electrode, $2.0 \mathrm{~mm}$ in diameter) was firstly incubated in piranha solution $\left(1: 3, \mathrm{~V} / \mathrm{V} ; 30 \% \mathrm{H}_{2} \mathrm{O}_{2}: 98 \% \mathrm{H}_{2} \mathrm{SO}_{4}\right)$ for $30 \mathrm{~min}$ and then it was abraded with $0.05 \mu \mathrm{m} \mathrm{Al}_{2} \mathrm{O}_{3}$ powder. $\mathrm{Au}$ electrode was successively sonicated in ethanol and water for $1 \mathrm{~min}$. The pretreated $\mathrm{Au}$ electrode was then electrochemically cleaned by 20 successive cyclic voltammograms (CVs) in $1.0 \mathrm{M} \mathrm{H}_{2} \mathrm{SO}_{4}$ over a potential range of $-0.3 \mathrm{~V}$ to $1.5 \mathrm{~V}$ at a scan rate of $0.1 \mathrm{~V} \mathrm{~s}^{-1}$. The cleaned Au electrode was immersed in $0.01 \mathrm{M}$ PBS solution ( $\mathrm{pH}$ 5.0) containing $2.0 \mathrm{mM}$ L-Cys for $12 \mathrm{~h}$ by self-assembled monolayer (SAM) techniques, which created the SAMs of L-Cys on Au electrode. The substrate was rinsed with water and dried under a stream of nitrogen. The obtained L-Cys/Au electrode was activated in $0.1 \mathrm{M}$ EDC and $0.1 \mathrm{M}$ NHS mixed solution for $30 \mathrm{~min}$, after being thoroughly rinsed, it was then soaked in $0.1 \mathrm{M}$ PBS (pH 6.82) containing 2.0 $\mu \mathrm{M}$ Lys for $12 \mathrm{~h}$ to obtain the Lys/L-Cys/Au modified electrode.

\subsection{Apparatus and measurements}

The electrochemical measurements including CVs, electrochemical impedance spectroscopy (EIS), and amperometric current-time (i-t) curves were carried out with CHI660C electrochemical workstation (Chenhua). The modified $\mathrm{Au}$ electrode, platinum wire, and $\mathrm{Ag} / \mathrm{AgCl}$ electrode $(3 \mathrm{M} \mathrm{KCl})$ were used as working electrode, auxiliary electrode, and reference electrode, respectively. Fluorescence spectra were performed on a RF-5301PC spectrophotometer (Shimadzu, Japan) using a $1.0 \mathrm{~cm}$ quartz cell at the excitation wavelength of $285 \mathrm{~nm}$ and the emission spectra were recorded between 295 and $450 \mathrm{~nm}$ (slit width: 5/5 nm). Circular Dichroism (CD) measurements were carried out on a J-810 spectrometer (Tokyo, Japan) in the wavelength range of 190-250 nm. Every CD spectrum was obtained from the average of three scans at a scan speed of $50 \mathrm{~nm} \mathrm{~min}^{-1}$.

\section{RESULTS AND DISCUSSION}

\subsection{Characterization of modified interface}

The Lys/L-Cys/Au modified electrode was successfully constructed by covalent bond of Lys onto the SAMs of L-Cys on the Au electrode (Scheme 1), which was firstly activated by EDC and NHS before the immobilization of Lys. The resulted Lys/L-Cys/Au electrode exhibits the on-off switching property at two typical $\mathrm{pH}$ values, $\mathrm{pH} 6.19$ and 12.13. Generally, as shown in Scheme 1, at $\mathrm{pH}$ 6.19, the protonated amino acid residues of Lys are positively charged due to its isoelectronic point 
(pI) at about 11.0 [23], which consequently causes a strong electrostatic attraction with negatively charged $\mathrm{Fe}(\mathrm{CN})_{6}{ }^{3-}$. This will make the probe go though the Lys/L-Cys film and the film turns to "on state". By contrast, at $\mathrm{pH} 12.13$, Lys carries negative charges with deprotonation of amino acid residues in Lys and causes the "off state" due to the electrostatic repulsion between Lys and $\mathrm{Fe}(\mathrm{CN})_{6}{ }^{3-}$.

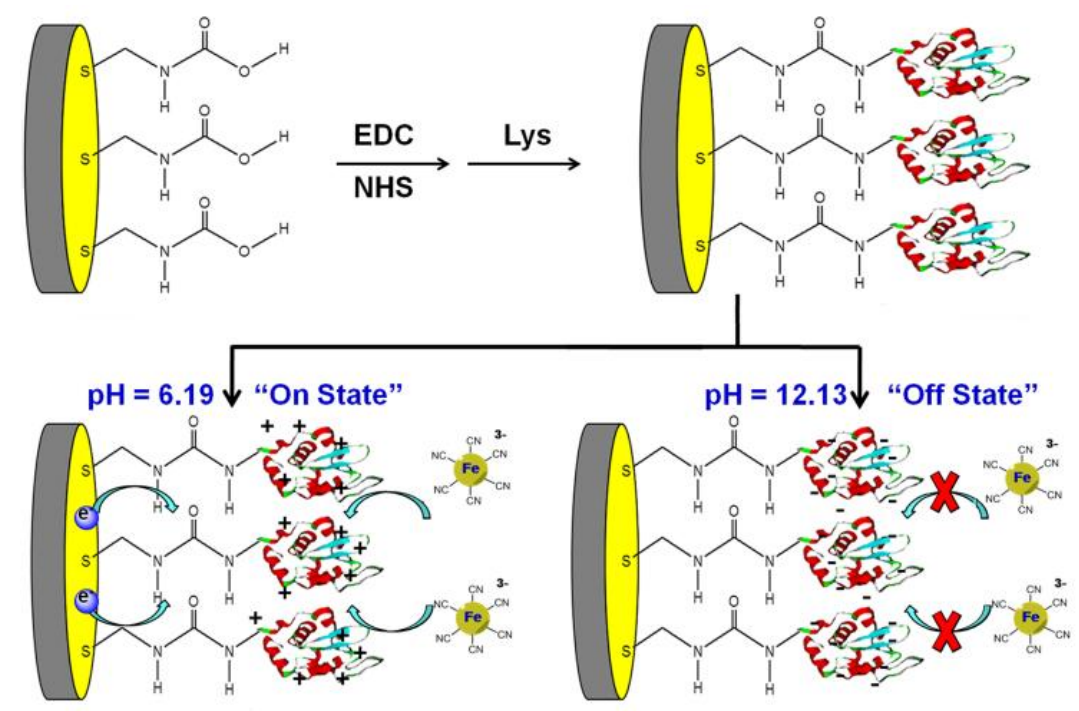

Scheme 1. Schematic diagram for the chemical bond of the Lys onto the SAMs of L-Cys on Au electrode and the on-off behavior of Lys/L-Cys/Au electrode at $\mathrm{pH} 6.19$ and 12.13

The modified procedure was investigated by EIS. The diameter of semicircles in EIS is usually used to represent the electron transfer resistance $\left(R_{\mathrm{et}}\right)$ of the probe in electron transfer. The changes of $R_{\text {et }}$ reflect the restricted diffusion of the probe through the modified film phase. As shown in Figure 1A, after L-Cys being self-assembled, the smaller semicircle of the bare Au electrode was increased largely by the SAMs of L-Cys, implying that the L-Cys layer obstructed the electron transfer of $\mathrm{Fe}(\mathrm{CN})_{6}^{3-}$ probe due to poor conductivity of L-Cys layer. However, with the covalent bond of Lys, the semicircle $R_{\text {et }}$ decreased obviously, indicating the enhanced direct transfer. The result is apparently opposite to that of the nonelectroactive protein modified on electrode in previous reports $[10,24]$. But, it exactly proves that the protonated Lys exhibits a strong electrostatic attraction with negatively charged $\mathrm{Fe}(\mathrm{CN})_{6}{ }^{3-}$ at $\mathrm{pH} 6.19$, leading to the decrease of semicircle $R_{\mathrm{et}}$ on the Lys/L-Cys/Au electrode.

$\mathrm{CV}$ and EIS of the Lys/L-Cys/Au electrode exhibited the on-off switching property at two typical $\mathrm{pH}$ values, $\mathrm{pH} 6.19$ and 12.13, which further confirmed the above conclusion. As shown in Figure 1B, the modified film shows a couple of reversible redox peaks at $\mathrm{pH} 6.19$, however, any redox peak cannot be obtained on the same electrode at $\mathrm{pH} 12.13$. Accordingly (Figure 1C), the $R_{\text {et }}$ of the modified film at pH 6.19 (inset) is very smaller than that at pH 12.13. Therefore, the "on" and "off" states of the Lys/L-Cys interface were obviously confirmed by CVs and EIS. This pH-dependent behavior cannot be attributed to the probe itself because $\mathrm{Fe}(\mathrm{CN})_{6}{ }^{3-}$ is $\mathrm{pH}$-independent [1], and thus, it results from the changes in charges on the Lys surface. 

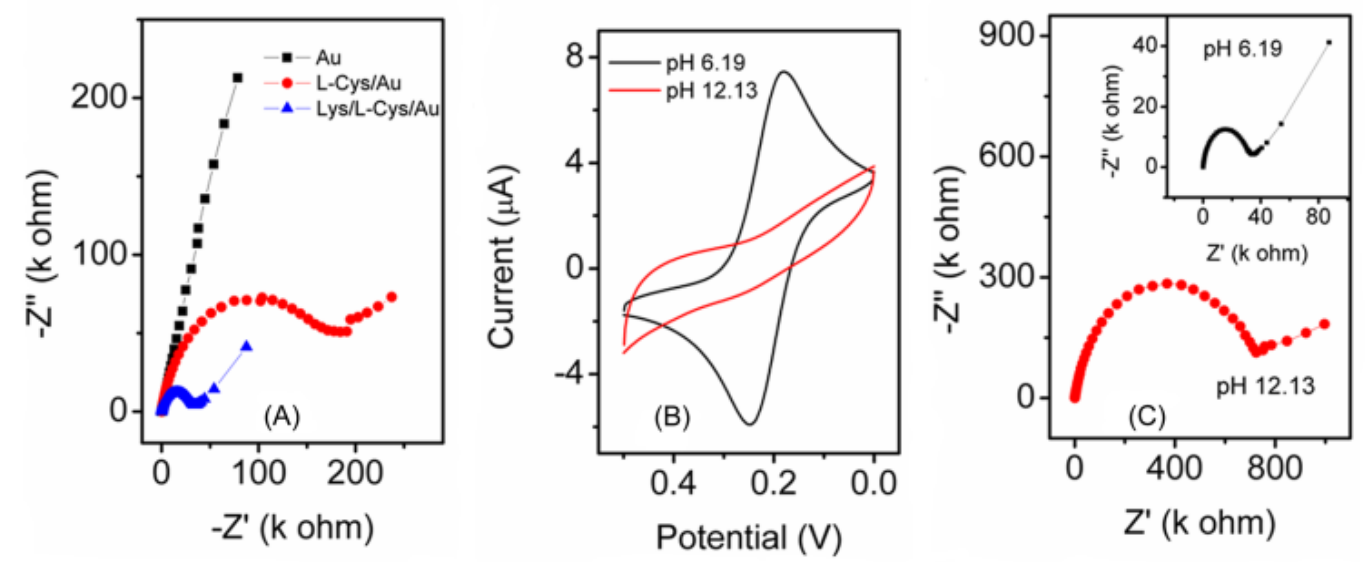

Figure 1. (A) EIS of the different modified electrodes in $1.0 \mathrm{mM} \mathrm{Fe}(\mathrm{CN})_{6}{ }^{3-}$ solution at $\mathrm{pH}$ 6.19. (B) and $(\mathrm{C}) \mathrm{CVs}$ and EIS of the Lys/L-Cys/Au electrode in $1.0 \mathrm{mM} \mathrm{Fe}(\mathrm{CN})_{6}{ }^{3-}$ solution at $\mathrm{pH} 6.19$ (inset) and 12.13, respectively.

\subsection{Electrochemical properties of modified electrode}

Figure $2 \mathrm{~A}$ shows the $\mathrm{CV}$ of $\mathrm{Fe}(\mathrm{CN})_{6}{ }^{3-}$ at the $\mathrm{Lys} / \mathrm{L}-\mathrm{Cys} / \mathrm{Au}$ electrode with various $\mathrm{pH}$ values from 2.55 to 12.13 . Obviously, the redox peak currents $\left(I_{\mathrm{p}}\right)$ and the peak potential difference $\left(\Delta E_{\mathrm{p}}\right)$ of $\mathrm{Fe}(\mathrm{CN})_{6}{ }^{3-}$ were substantially influenced by the $\mathrm{pH}$ of solution. As shown in Figure $2 \mathrm{~B}, \Delta E_{\mathrm{p}}$ increased gradually with the increase of the $\mathrm{pH}$ value of solution. The reduction peak current $\left(I_{\mathrm{pc}}\right)$ decreased slowly before $\mathrm{pH} 8.57$ and then decreased drastically when $\mathrm{pH}$ value was larger than 8.57 . When $\mathrm{pH}$ value is larger than $\mathrm{pI}$ of Lys (11.0), the redox signal of $\mathrm{Fe}(\mathrm{CN})_{6}{ }^{3-}$ could hardly be observed. The results reveal that the electrostatic attraction induced by the protonation and deprotonation of Lys on electrode are mainly responsible for the $\mathrm{pH}$-switchable property. Therefore, the Lys/L-Cys/Au electrode can perform reversible $\mathrm{pH}$-sensitive "on-off” functions.
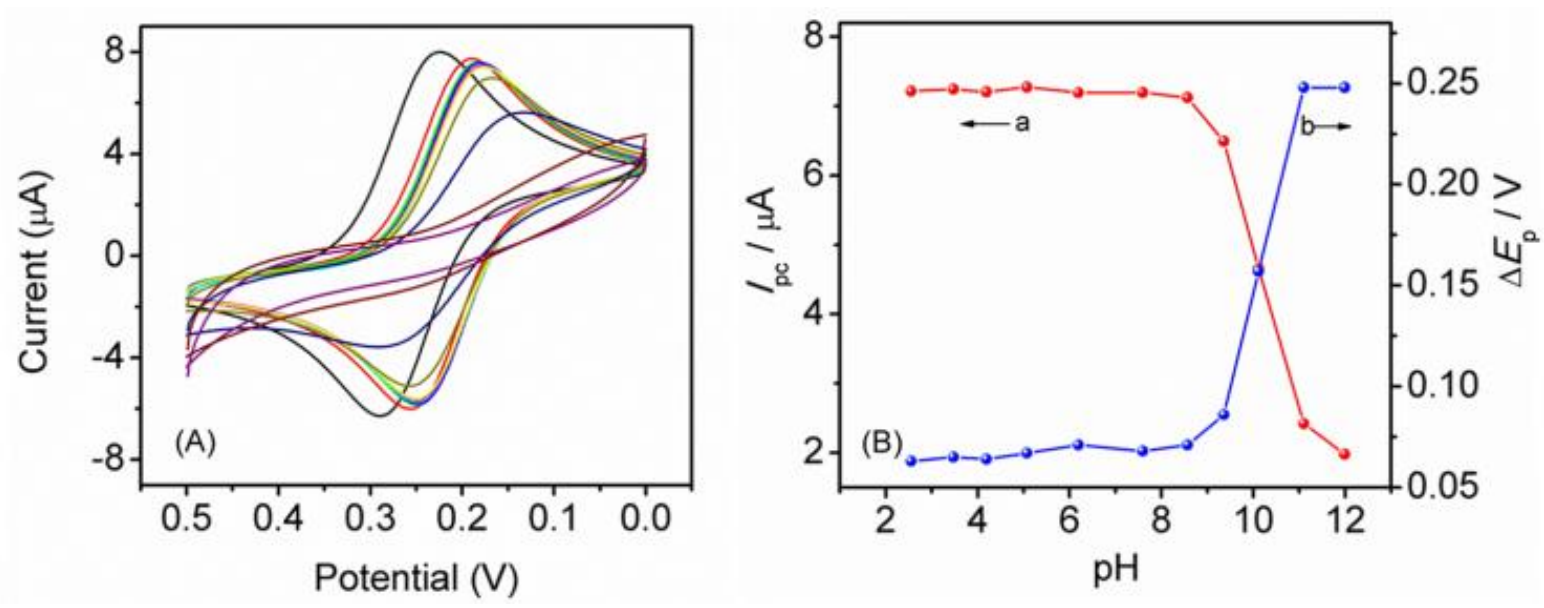

Figure 2. (A) $\mathrm{CVs}$ of the Lys/L-Cys/Au electrode in $1.0 \mathrm{mM} \mathrm{Fe}(\mathrm{CN})_{6}{ }^{3-}$ solution with various $\mathrm{pH}$ (from left to right: $2.55,3.47,4.19,5.07,6.19,7.59,8.57,9.36,10.11,11.10,12.13$ ). (B) The current of reduction peak $\left(I_{\mathrm{pc}}\right)$ and peak potential difference $\left(\Delta E_{\mathrm{p}}\right)$ at relative $\mathrm{pH}$. 


\subsection{Protein conformation}

It is well known that the conformation of protein changes with varying $\mathrm{pH}$ of solution. In order to evaluate the effects of $\mathrm{pH}$ on the conformational alteration of Lys, the intrinsic fluorescence and circular dichroism (CD) of Lys in 0.1 M PBS with different $\mathrm{pH}$ were investigated. Lys contains six tryptophan (Trp) residues and three tyrosine (Tyr) residues (inset in Figure3A). Among Trp residues, $\operatorname{Trp} 28$ 108, 111, and 123 residues are present in the $\alpha$-domain, and Trp 62 and 63 residues are located at the hinge region between $\alpha$ and $\beta$-domains of the protein [25]. Trp 62 and 108 residues are partially exposed to the solvent and not close to cystine or methionine sulfurs, which are responsible for the most intrinsic fluorescence of native Lys and reflect the conformational alteration of protein [20]. Figure 3A shows that the fluorescence of Lys decrease gradually with the decreasing of $\mathrm{pH}$ from 8.57 to 2.55 without obvious shift in the maximum emission wavelength $\left(\lambda_{\max }\right)$, indicating the tertiary structure of Lys is disturbed but keeps relative stable even at $\mathrm{pH}$ as low as 2.55 . However, as $\mathrm{pH}$ is higher than 8.57 , the fluorescence intensity decreases dramatically and the $\lambda_{\max }$ shifts from $338 \mathrm{~nm}$ at $\mathrm{pH} 8.57$ to $342 \mathrm{~nm}$ at $\mathrm{pH}$ 12.13. At the same time, a shoulder peak at $308 \mathrm{~nm}$ appeared, which was attributed to the fluorescence of Tyr residues [26]. The phenomena confirm the tertiary structure of Lys was unfolded in the alkaline solution [23]. The secondary structure of Lys in alkaline solution was monitored by far UV-CD spectra (Figure3B). The negative peaks at 208 and $222 \mathrm{~nm}$, which are assigned to the $n-\pi^{*}$ transition of the carbonyl group and the parallel exactions of $\pi-\pi^{*}$ transition of peptide, respectively, reflect the $\alpha$-helices content of protein [26]. The CD shows no apparent change between $\mathrm{pH} 7.59$ and 11.10 (Figure3B), indicating that Lys retains all the features of secondary structure found in the native protein.
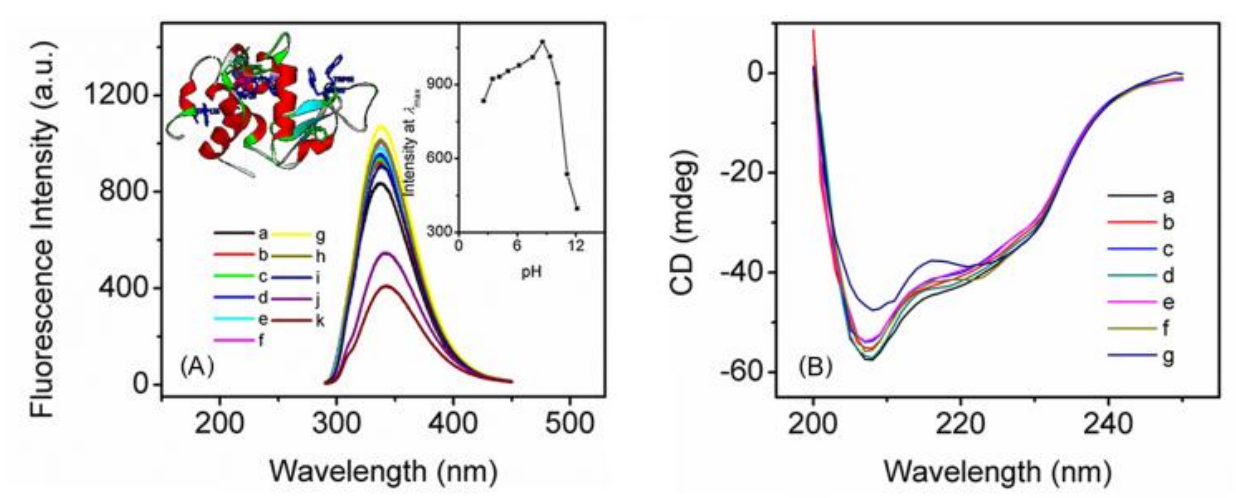

Figure 3. (A) Fluorescence spectra of $2.0 \mu \mathrm{M}$ Lys in $0.1 \mathrm{M}$ PBS at various pH (from a to k: 2.55, 3.47, 4.19, 5.07, 6.19, 7.59, 8.57, 9.36, 10.11, 11.10, 12.13, Inset: three-dimensional structure of Lys with Trp (blue) and Tyr (green) residues, PDB: 2CDS). (B) The CD spectra of $4.0 \mu \mathrm{M}$ Lys in $0.1 \mathrm{M}$ PBS at various $\mathrm{pH}$ (from a to $\mathrm{g}: 6.19,7.59,8.57,9.36,10.11,11.10,12.13$ ).

However, at $\mathrm{pH} 12.13$, two peaks decrease obviously to a minimum value (Figure 3B), which suggest that the secondary structure of Lys was unfolded partially $[25,26]$. Thus, from $\mathrm{pH} 2.55$ to 11.10 , the tertiary structure of Lys altered but its secondary structure did not unfold obviously until $\mathrm{pH}$ up to 12.13 , which may be the reason for the potential change in Figure 2A. Moreover, when pH was 
adjusted from 12.13 to $\mathrm{pH} 6.19$ by adding $\mathrm{HCl}$, the $\mathrm{CD}$ spectrum could reversibly return to its original state except for the dilute effect of concentration. The results suggest that reversible conformational change with various $\mathrm{pH}$ also plays an important role for the $\mathrm{pH}$-switchable property, which should be paid more attention in protein-based electrochemical sensors.

\section{4. pH-switchable property of Lys/L-Cys film}

The $\mathrm{pH}$-switchable property of Lys/L-Cys/Au electrode toward $\mathrm{Fe}(\mathrm{CN})_{6}{ }^{3-}$ was evaluated by the recorded CVs for 7 cycles (Figures 4A and 4B). By switching the solution pH between 6.19 and 12.13, reversible redox couples of $\mathrm{Fe}(\mathrm{CN})_{6}{ }^{3-}$ at $\mathrm{Lys} / \mathrm{L}-\mathrm{Cys} / \mathrm{Au}$ electrode could be obtained repeatedly at $\mathrm{pH}$ 6.19 but the redox behavior of the probe was completely suppressed at $\mathrm{pH} \mathrm{12.13.} \mathrm{After} 7$ running, significant difference in current between each cycle for both $\mathrm{pH}$ values were not found, which indicates the excellent reproducibility and stability of the Lys/L-Cys film and ideal intelligent interface for electroanalysis.

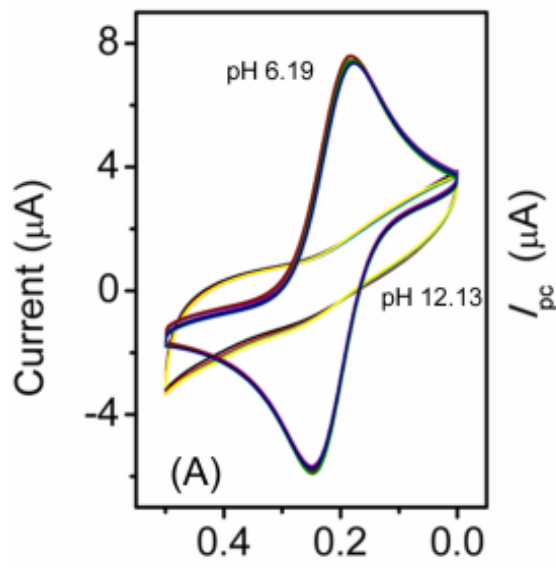

Potential (V)

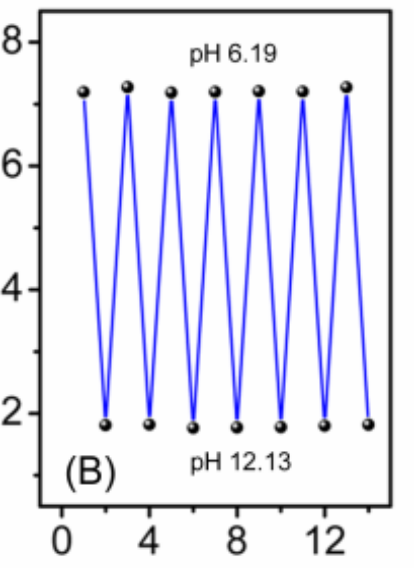

Cycle number

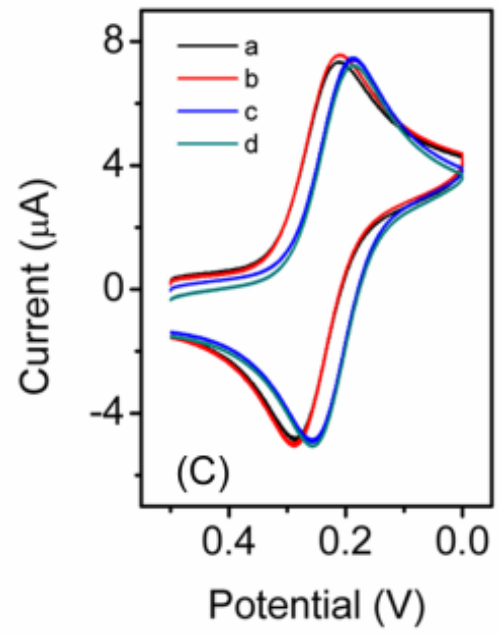

Figure 4. (A) $\mathrm{CVs}$ of the Lys/L-Cys/Au electrode in $1.0 \mathrm{mM} \mathrm{Fe}(\mathrm{CN})_{6}{ }^{3-}$ solution at $\mathrm{pH} 6.19$ and 12.13 for 7 times, respectively. (B) Dependence of $I_{\mathrm{pc}}$ on the cycle number when $\mathrm{pH}$ of solution switched between pH 6.19 and 12.13. (C) CVs of the Lys/L-Cys/Au electrode after 10 successively scanning without time interval (curves a and $b$ ) and after waiting for 2 minutes (curves $\mathrm{c}$ and $\mathrm{d}$ ).

During the experiments, a phenomenon was found that the redox potential of $\mathrm{Fe}(\mathrm{CN})_{6}{ }^{3-}$ at Lys/L-Cys/Au electrode would change after continuous scans. As shown in Figure 4C, curves a and b are the $\mathrm{CVs}$ of $\mathrm{Fe}(\mathrm{CN})_{6}{ }^{3-}$ after 10 successively scanning without time interval. However, when the modified electrode was scanned after waiting for 2 minutes, the redox peaks of $\mathrm{Fe}(\mathrm{CN})_{6}{ }^{3-}$ shifted to the negative potential and it was repeated on the same potential after 2 minutes (curves $\mathrm{c}$ and $\mathrm{d}$ ). The potential shift is probably ascribed to the change in the protein conformation during the voltammetric scan. The structure of Lys may be constricted or bent slightly toward the electrode during successively scanning, which decreases the inhibition of protein toward the probe and leads to positive shift of potential. After stopping for a short time, Lys on the electrode returns to the native state resulting in 
the recovery of redox potential. Therefore, for the protein-based electrochemical sensors, the conformation of protein on the electrode should be concerned and kept the original state during the application.

\subsection{The bioelectrocatalysis of the Lys/L-Cys/Au electrode}

The $\mathrm{pH}$-switchable property of the Lys/L-Cys/Au electrode could be used to control or modulate electrocatalytic reduction of $\mathrm{H}_{2} \mathrm{O}_{2}$. In the presence of $3.5 \mathrm{mM} \mathrm{H}_{2} \mathrm{O}_{2}$, dramatic increase in the reduction peak along with obvious decrease in oxidation peak was found on the Lys/L-Cys/Au electrode in $\mathrm{Fe}(\mathrm{CN})_{6}{ }^{3-}$ solution at $\mathrm{pH} 6.19$ (curves a and $\mathrm{b}$ in Figure 5A), indicating an evident electrocatalytic reduction of $\mathrm{H}_{2} \mathrm{O}_{2}$. However, in $\mathrm{pH} 12.13$ solution, no evident response for the redox current was observed (curves a and $b$ in Figure 5B), which suggested that Lys/L-Cys film became off state toward $\mathrm{Fe}(\mathrm{CN})_{6}^{3-}$.
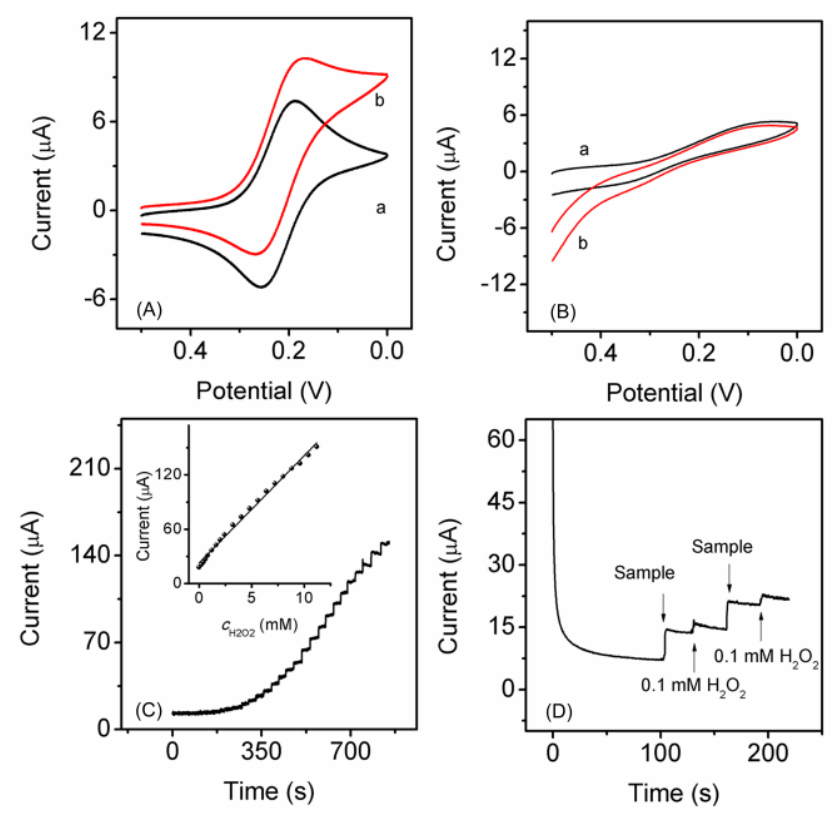

Figure 5. $\mathrm{CVs}$ of the Lys/L-Cys/Au electrode in $1.0 \mathrm{mM} \mathrm{Fe}(\mathrm{CN})_{6}{ }^{3-}$ (curve a), containing $0.2 \mathrm{mM}$ $\mathrm{H}_{2} \mathrm{O}_{2}$ (curve b) at $\mathrm{pH} 6.19$ (A) and $\mathrm{pH} 12.13$ (B). (C) Current-time curves of the Lys/L-Cys/Au electrode with successive additions of $\mathrm{H}_{2} \mathrm{O}_{2}$ at $0.18 \mathrm{~V}$ (Inset: plots of current $v s \mathrm{H}_{2} \mathrm{O}_{2}$ concentration). (D) Amperometric responses of the sensor with the additions of diluted disinfector samples and $\mathrm{H}_{2} \mathrm{O}_{2}$ standard solution.

The bioelectrocatalysis of the Lys/L-Cys/Au electrode at "on" state was further investigated by chronoamperometry. As shown in Figure 5C, upon the successive additions of $\mathrm{H}_{2} \mathrm{O}_{2}$, the modified electrode quickly responded to the reduction of $\mathrm{H}_{2} \mathrm{O}_{2}$ and the catalytic currents increased linearly with the $\mathrm{H}_{2} \mathrm{O}_{2}$ concentration in the range of $0.2-11.2 \mathrm{mM}$ (Figure 5C). The response sensitivity was calculated to be $379 \mu \mathrm{A} \mathrm{mM} \mathrm{cm}^{-2}$ ( $\mathrm{R} 0.9969$ ) and the limit of detection for $\mathrm{H}_{2} \mathrm{O}_{2}$ was evaluated to be $18.2 \mu \mathrm{M}$, which are comparable to those of the previously reported $\mathrm{H}_{2} \mathrm{O}_{2}$ sensors [27-29]. 
In order to evaluate the practical application of the Lys/L-Cys/Au electrode, diluted disinfector samples have been performed by standard addition method using the proposed sensor. As shown in Figure 5D, the average concentration of $\mathrm{H}_{2} \mathrm{O}_{2}$ was determined to be $238.1 \mu \mathrm{M}$ with the acceptable recoveries of $106.6 \%$ and $103.7 \%$. The results suggested that the presented presented Lys/L-Cys/Au interface exhibited the appreciable practicality for detecting $\mathrm{H}_{2} \mathrm{O}_{2}$.

\subsection{Stability and reproducibility of the Lys/L-Cys/Au electrode}

Figure 6A shows the operational stability of Lys/L-Cys/Au electrode. The current response for $10.0 \mu \mathrm{M} \mathrm{H}_{2} \mathrm{O}_{2}$ kept stable with 17 mincontinuous response. Moreover, after being stored 10 days, the prepared electrode shows the same response towards $0.2 \mathrm{mM} \mathrm{H}_{2} \mathrm{O}_{2}$ (Figure 6B). The results reveal that the Lys/L-Cys/Au electrode can show excellent operational and storage stability if it is used as electrochemical sensor for detecting $\mathrm{H}_{2} \mathrm{O}_{2}$.

Four modified electrodes with the same treatment on different Au electrodes have been used to study the inter-reproducibility (Figure 6C). According to the current response, the relative standard deviation was less than $5.2 \%$, indicating acceptable inter-reproducibility. Moreover, the good intrareproducibility for the prepared electrode can be evaluated by its $\mathrm{pH}$-switchable property in Figure 4.

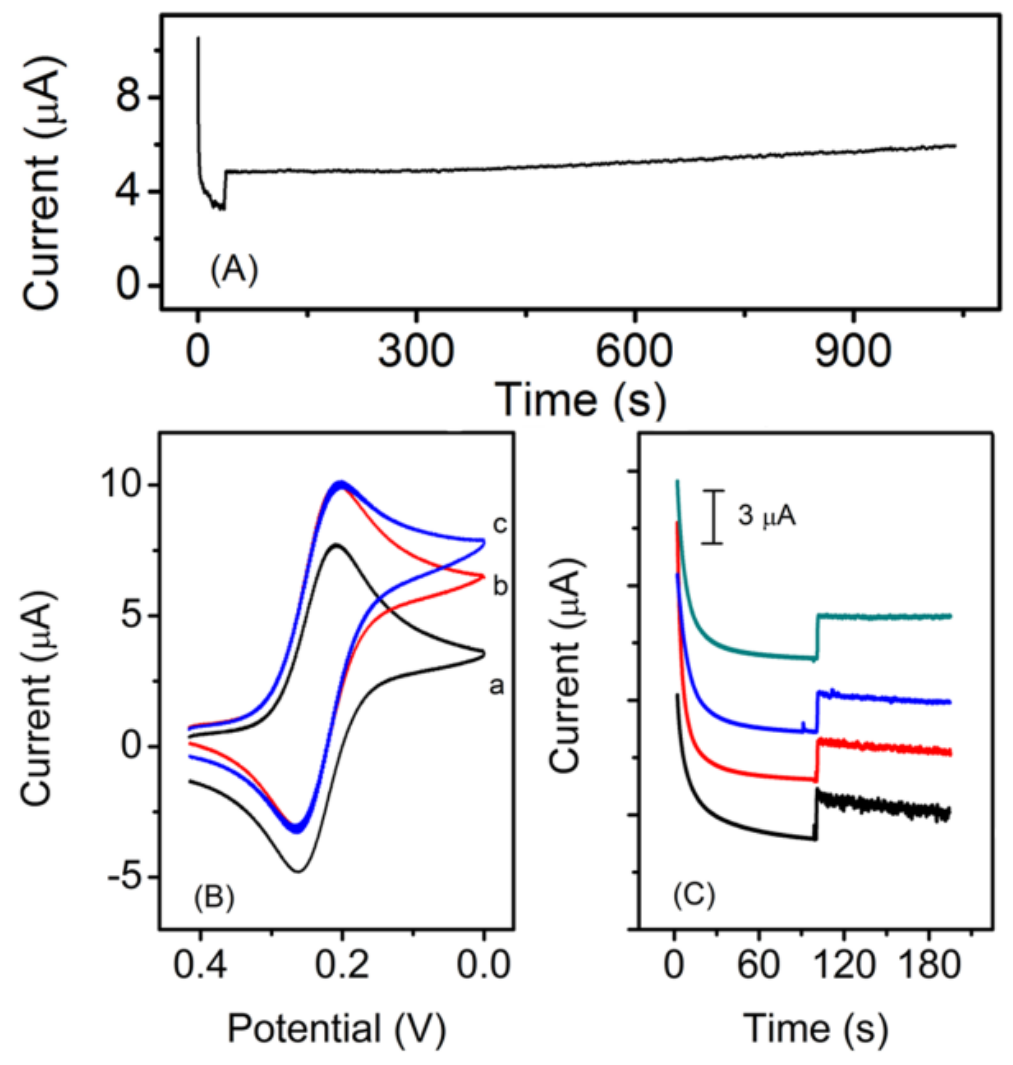

Figure 6. (A) Operational stability of the Lys/L-Cys/Au electrode with continuous response on 50.0 $\mu \mathrm{M} \mathrm{H}_{2} \mathrm{O}_{2}$ for $17 \mathrm{~min}$. (B) $\mathrm{CV}$ of the Lys/L-Cys/Au electrode in the absence (a) and presence of $0.2 \mathrm{mM} \mathrm{H}_{2} \mathrm{O}_{2}$ before (b) and after (c) 10 days. (C) Amperometric responses of four sensors on $0.1 \mathrm{mM} \mathrm{H}_{2} \mathrm{O}_{2}$. 


\section{CONCLUSIONS}

In conclusion, Lys was covalently bonded with the L-Cys assembled film on Au electrode to obtain the intelligent interface of Lys/L-Cys film, which exhibited a $\mathrm{pH}$-sensitive on-off property toward the electroactive probe of $\mathrm{Fe}(\mathrm{CN})_{6}{ }^{3-}$. At $\mathrm{pH}$ 6.19, the Lys/L-Cys/Au electrode showed the "on" state and exhibited good bioelectrocatalysis for the reduction of $\mathrm{H}_{2} \mathrm{O}_{2}$, which was closed by adjusting the $\mathrm{pH}$ to 12.13. Furthermore, as an electrochemical sensor, the presented electrode showes good catalytic ability in the presence of electroactive probe, and also exhibites excellent stability and reproducibility. Based on the conformational analysis and electrochemical properties, the electrostatic interaction between Lys and the probe resulted in the $\mathrm{pH}$-switchable behavior, and the protein conformation on the electrode was responsible for the reproducibility and stability of the Lys/L-Cys film.

\section{ACKNOWLEDGEMENTS}

This work was supported by the national natural science foundation of China $(21405019,91643113$, 21201037), natural science foundation of Anhui province (1408085QB39, 1708085MB43), key projects of support program for outstanding young talents in Anhui province colleges and Universities (gxyqZD2016192, gxyqZD2016193), the foundation of the state key laboratory of chemo/biosensing and chemometrics in Hunan University (2015019), the major project of biology discipline construction in Anhui province (2014), and Quality Project of Higher Education of Anhui Province (2016jyxm0749). Thanks for the talent support program in Virginia Polytechnic Institute and State University and Fuyang Normal University.

\section{References}

1. Y. Song, H. Liu, H. Tan, F. Xu, J. Jia, L. Zhang, Z. Li and L. Wang, Anal. Chem., 86 (2014) 1980.

2. X. Miao and N.F. Hu, J. Electroanal. Chem., 660 (2011) 114.

3. A.P. de Silva, H.Q.N. Gunaratne and C.P. McCoy, J. Am. Chem. Soc., 119 (1997) 7891.

4. M. Frensemeier, J.S. Kaiser, C.P. Frick, A.S. Schneider, E. Arzt, R.S. Fertig III and E. Kroner, Adv. Funct. Mater., 25 (2015) 3013.

5. T. Leijtens, E.T. Hoke, G. Grancini, D.J. Slotcavage, G.E. Eperon, J.M. Ball, M. De Bastiani, A.R. Bowring, N. Martino, K. Wojciechowski, M.D. McGehee, H.J. Snaith and A. Petrozza, Adv. Energy Mater., 5 (2015) 1500962.

6. O. Parlak, A.P.F. Turnera and A. Tiwari, J. Mater. Chem. B, 3 (2015) 7434.

7. N.P. Shetti, D.S. Nayak, S.J. Malode and R.M. Kulkarni, J. Electrochem. Soc., 164 (2017) B3036.

8. H. Wu, S. Fan, X. Jin, H. Zhang, H. Chen, Z. Dai and X. Zou, Anal. Chem., 86 (2014) 6285.

9. P. Sun, N.F. Hu and H.Y. Liu, Electroanalysis, 23 (2011) 513.

10. Z. Pan, X. Liu, J. Xie, N. Bao, H. He, X. Li, J. Zeng and H. Gu, Colloid Surface B, 129 (2015) 169.

11. T.K. Tam, M. Pita, O. Trotsenko, M. Motornov, I. Tokarev, J. Halámek, S. Minko and E. Katz, Langmuir, 26 (2010) 4506.

12. H. Yao and N. F. Hu, J. Phys. Chem. B, 114 (2010) 3380.

13. S. L. Song and N. F. Hu, J. Phys. Chem. B, 114 (2010) 3648.

14. D. Liu, H.Y. Liu and N.F. Hu, J. Phys. Chem. B, 116 (2012) 1700.

15. H. Wu, S. Fan, W. Zhu, Z. Dai and X. Zou, Biosens. Bioelectron., 41 (2013) 589.

16. C. Yu, W. Ji, L. Gou, N. Bao and H. Gu, Electrochem. Commun., 13 (2011) 1502.

17. H. Wu, L. Lin, P. Wang, S. Jiang, Z. Dai and X. Zou, Chem. Commun., 47 (2011) 10659. 
18. H. Wu, X. Wang, M. Qiao, H. Zhang, X. Jin and S. Fan, Sensor Actuat. B: Chem., 221 (2015) 694.

19. L. Xing, K. Lin, X. Zhou, S. Liu and Y. Luo, J. Phys. Chem. B, 120 (2016) 10660.

20. B. Chen, H. Zhang, W. Xi, L. Zhao, L. Liang and Y. Chen, J. Mol. Struct., 1076 (2014) 524.

21. D.V. Laurents and R.L. Baldwin, Biochemistry, 36 (1997) 1496.

22. S. Venkataramani, J. Truntzer and D.R. Coleman, J. Pharm. Bioallied Sci., 5 (2013) 148.

23. M. Hameed, B. Ahmad, K.M. Fazili, K. Andrabi and R.H. Khan, J. Biochem., 141 (2007) 573.

24. Y. Boonyasit, W. Laiwattanapaisal, O. Chailapakul, J. Emnéus and A.R. Heiskanen, Anal. Chem., 88 (2016) 9582.

25. S. Millan, L. Satish, S. Kes, Y.S. Chaudhary and H. Sahoo, J. Photoch. Photobio. B, 162 (2016) 248.

26. H. Wu, P. Wang, X. Hu, Z. Dai and X. Zou, Talanta, 84 (2011) 881.

27. D.D. Justino, I.L. Torres, R.R. de Cássia Silva Luz and F.S. Damos, Electroanalysis, 27 (2015) 1202.

28. S. Liu, J.Q. Tian, L. Wang, H.L. Li, Y.W. Zhang and X.P. Sun, Macromolecules, 43 (2010) 10078.

29. X. Yang, F.B. Xiao, H.W. Lin, F. Wu, D.Z. Chen and Z.Y. Wu, Electrochim. Acta, 109 (2013) 750.

(C) 2018 The Authors. Published by ESG (www.electrochemsci.org). This article is an open access article distributed under the terms and conditions of the Creative Commons Attribution license (http://creativecommons.org/licenses/by/4.0/). 